\title{
BENEFITS DERIVED BY SMES THROUGH IMPLEMENTATION OF TQM
}

\author{
Yogesh A. Chauhan ${ }^{1}$ \\ ${ }^{1}$ Associate Professor, Mechatronics Engineering Department, G.H.Patel College of Engineering \& Technology, \\ Gujarat, India,
}

\begin{abstract}
Small and medium scale enterprises have contributed in the growth of the country's economy. Being the suppliers for various components and sub assemblies to the large scale enterprises these companies are certainly required to continuously work towards the betterment of quality. There are various reasons why companies follow various Quality Management practices. ISO9001 and TQM are the most preferred out of them. TQM is about changing the entire working pattern and becoming more systematic in terms of everything which a company does. It also focuses on overall growth of the company with a special emphasis on the quality. Following TQM principles certainly bring good results in terms of productivity, reduction of rejection, cost reduction etc. It also helps in reducing gap between management and employees which in turn leads to several other benefits. This research paper is bringing out the facts about the positives derived by SMEs as a result of following TQM principles with the help of a survey of manufacturing companies.
\end{abstract}

Keywords: TQM, ISO9001, SMES

\section{INTRODUCTION}

The industrial scenario is becoming very challenging and demanding. May it be a small firm or a large scale firm, every firm is facing a cut throat competition. This has forced the industrial units to work on either reducing the cost and/or to improve the quality of the products they are manufacturing or both to sustain themselves. In order to reduce the cost without compromising with the quality they have to find out ways and means with which they have to work. Basically a proper system has to be devised and followed so that the results can be achieved as expected. ISO9001 model is one of such models which gives a readymade system directions and the organizations are required to make a system according to the guidelines and objectives given by ISO. Many organizations are following the same and got certified with ISO9001. This certification certainly helped them to have a better and systematic approach. Quality improvement also took place. Employees got absolute clarity in terms of their role and hence they could perform better. SMEs also followed the trend and got themselves certified with ISO9001 to enjoy benefits associated with the same.

However TQM is considered to be an enhanced way of dealing with the quality. TQM is actually a management philosophy which takes the organization to think beyond the product quality. It has several key elements like quality chain, process management, continuous improvement, employee empowerment, team working \& synergy, creativity \& innovation, benchmarking, housekeeping; and kaizen. All this elements bring several benefits attached with them. It requires participation of all the members of the organization which leads to employee satisfaction and the human force stays highly motivated in turn helps in improvement in the productivity. It also requires effective leadership and the top management has to be committed towards the philosophy of TQM.

Demirbag et al. (2006) [1] defined TQM as: "A holistic management philosophy aimed at continuous improvement in all functions of an organization to deliver services in line with customer's needs or requirements under the leadership of top-management".

Christofi et al. (2008) [2] defined TQM as: "A supply-chainwide quality commitment-from the supplier, to the producer, to the consumer-of an organization, in order to achieve excellence in production and service management".

Sustained implementation of TQM can result in benefits such as improvement in quality of products and services, productivity, reliability, market share, revenue, profits which will lead to overall growth of an organization. [3]

\section{LITERATURE REVIEW}

Lee and Kelce, (2003) [4] investigated the existing status of TQM practices in 112 SMEs (manufacturing firms) of China and its impact on their performance. It was found that manufacturing process of these small firms was not an obstacle to the implementation of TQM; instead it was the size of firm, which posed as a threat for implementation. Research showed that majority of the firms were new to TQM practices and that it was initiated by their top management. A positive influence of TQM was observed on performance as waste, inventory and costs was reduced, and an increase in sales was observed. In the same manner, performance of SMEs was observed in (Malaysia by Sohail and Hoong, 2003 [5]; in India by Mahadevappa et al., 2004 
[6]; in Portugal by Sousa et al., 2005 [7]; in Spain by Bou and Beltrain, 2005 [8]; and in Turkey by Demirbag and Zaim, 2006 [1]) .

All researchers were of the view that ISO certification should be acquired by the SMEs, and, ISO quality management systems should be integrated with TQM for continuous improvement of the overall business performance.

Shivakumar B. Burli et al. [9] in their research paper with the help of a survey of ISO \& Non ISO manufacturing firms of Karnataka \& Maharashtra stated that, If TQM policies and practices are applied in a positive manner in manufacturing SMEs, it will significantly contribute in their performance in terms of quality and customer satisfaction. ISO has been adapted in many SMEs but certain TQM practices observed to be weak and hence, need management attention. The study brought out that the manufacturing SME's must accept, and practice TQM practices to enhance performance and customer satisfaction. The study also revealed that ISO certified firms demonstrate higher level of TQM practices as compared to Non-ISO SMEs. Hence the firms must initiate TQM implementation via ISO and then slowly expand to address soft dimensions like people management to achieve continuous improvement of processes and increased level of customer satisfaction.'

S.D.Kalpande et al. [10] cited that 'TQM is rising above the system- oriented approach and makes the connections to the needs of the customers in the society and the improvement of the quality of the product and the organization as a whole.' (Rao and Tang, 1996)[11]

Daniel I. Prajogo, Amrik S. Sohal [12] suggested that the fundamental premise of TQM is that the costs of poor quality are far greater than the costs of developing processes that produce high quality products and services.

The authors also cited Philips et al. [13] concluding that quality creates a competitive advantage through customer loyalty as well as it minimizes customer sensitivity to price. With the empirical study, they also gave a finding that product quality exerts a beneficial effect on cost position via market share. According to TQM, however, quality directly impacts on cost reduction at an operational level rather than via market share. Deming [14] affirmed that organizations could enhance competitiveness by improvement in the quality resulting in reduction of cost through the elimination of rework and scrap.

The authors [12] concluded that 'a harmony between differentiation strategy, TQM practices and organization performance in terms of quality and innovation. TQM's role is more effective for pursuing differentiation in terms of quality rather than innovation.' Further they added that 'TQM only partially mediates the relationship between differentiation strategy and the three performance variables (product quality, product innovation, and process innovation).'

\section{METHODOLOGY}

A survey was carried out with 20 Small and Medium Scale companies from the manufacturing sector. The sampling was carried out on the basis of convenience. The overall survey was conducted with a sample of 182 respondent firms in the required category of SMEs. However a very few SMEs were found following TQM principles. The tool used for the survey was a prescribed questionnaire with mostly closed ended questions. One section out of which, was dedicated to TQM related questions. The respondents were given with a list of probable benefits derived by them as a result of implementing TQM. They were to give their response according to the extent to which they have derived those benefits in their organization.

\section{FINDINGS}

Following section indicates the benefits derived as per the extent to which the firms have experienced them. [15]

\subsection{Customer Satisfaction has Shown Improvement}

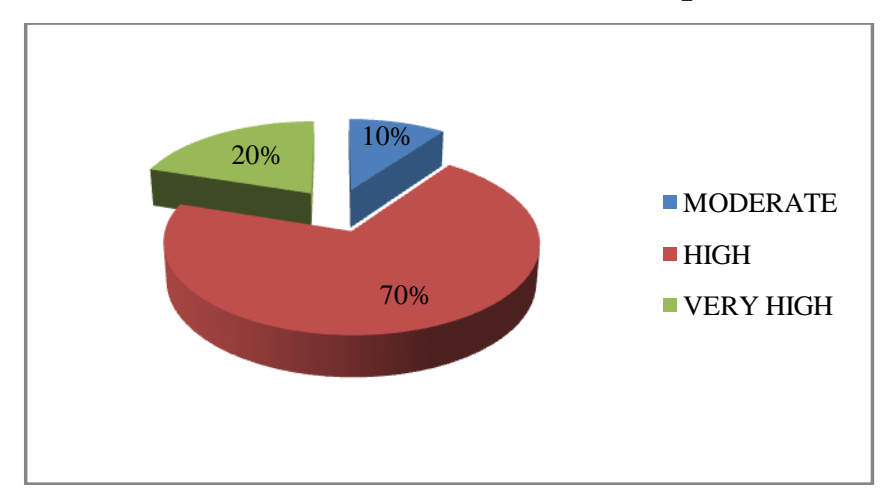

Fig.1 Improvement in Customer Satisfaction

It is expected that following TQM principles will improve customer satisfaction for several reasons. From the above fig. 1 , this fact is evident. $20 \%$ of the respondents confirmed that they experienced improvement in the customer satisfaction to a very high level, $70 \%$ of them to a high level and remaining $10 \%$ to a moderate level.

\subsection{The Number of Products/Service Defects,} Errors or Failures has decreased

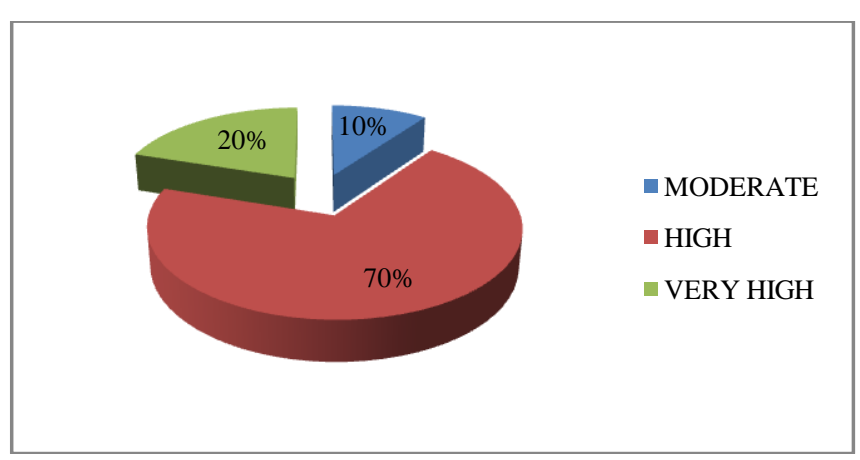

Fig. 2 Decrease in Failures in products/service defects, errors or failures 
When inquired regarding the reduction in the number of product/service failures, all the respondents agreed that there was a remarkable change. As high as $70 \%$ of the respondents felt that the errors and failures had decreased to a high extent. $20 \%$ felt that it was to a very high extent while $10 \%$ felt it was to a moderate extent. (Fig.2)

\subsection{The Number of Customer Complaints has}

\section{decreased}

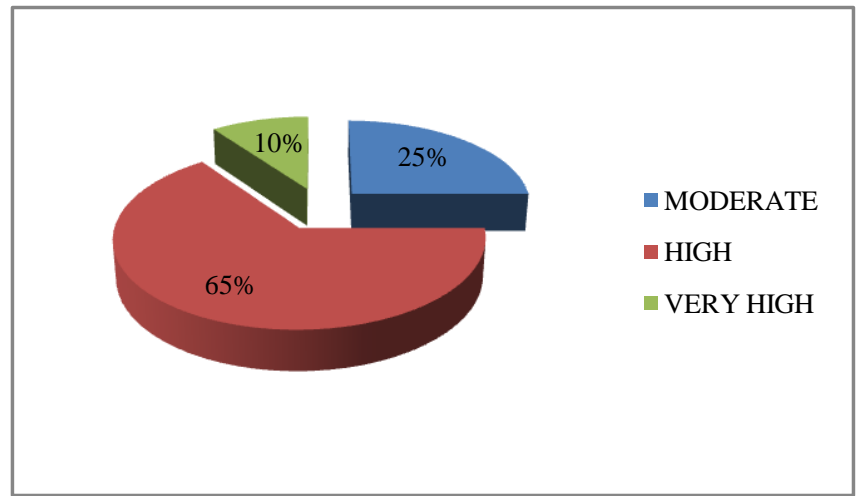

Fig. 3 Decrease in number of Customer Complaints

As can be seen from the figure 3,65\% of the respondents felt that there was decrease in the number of customer complaints to a high extent. $10 \%$ felt it was to a very high extent while $25 \%$ felt it was to a moderate extent. This clearly indicates that all the respondents derived this benefit of reduction in the customer complaints as a result of implementation of TQM policies.

\subsection{Financial Results have improved}

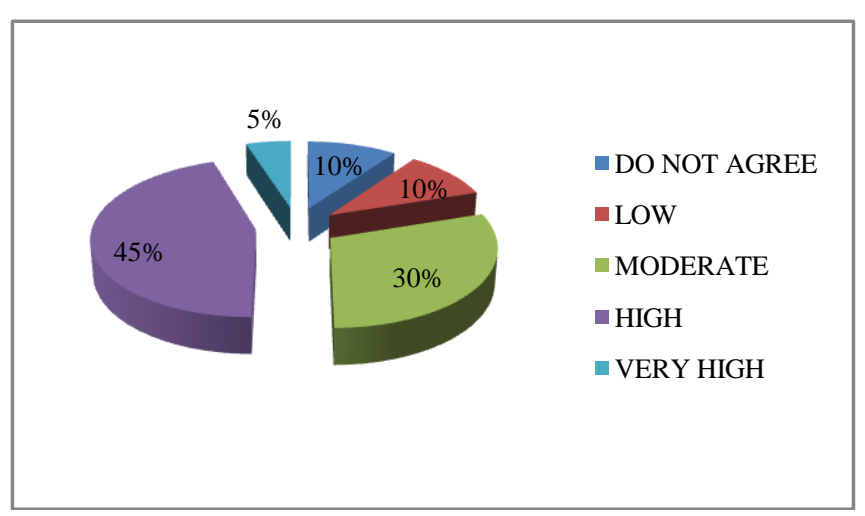

Fig. 4 Improvement in financial results

Nearly $50 \%$ of the respondents, as can be inferred from the above figure 4 , felt that the financial results have improved to high to very high extent. $30 \%$ of the respondents felt that it was to a moderate extent while $10 \%$ felt that it was to a low extent. Rest of them did not see any improvement in the financial results. It seems that firms do not realize a very great improvement on the financial front with TQM implementation.

\subsection{Company has developed a Culture that}

\section{Emphasizes Quality}

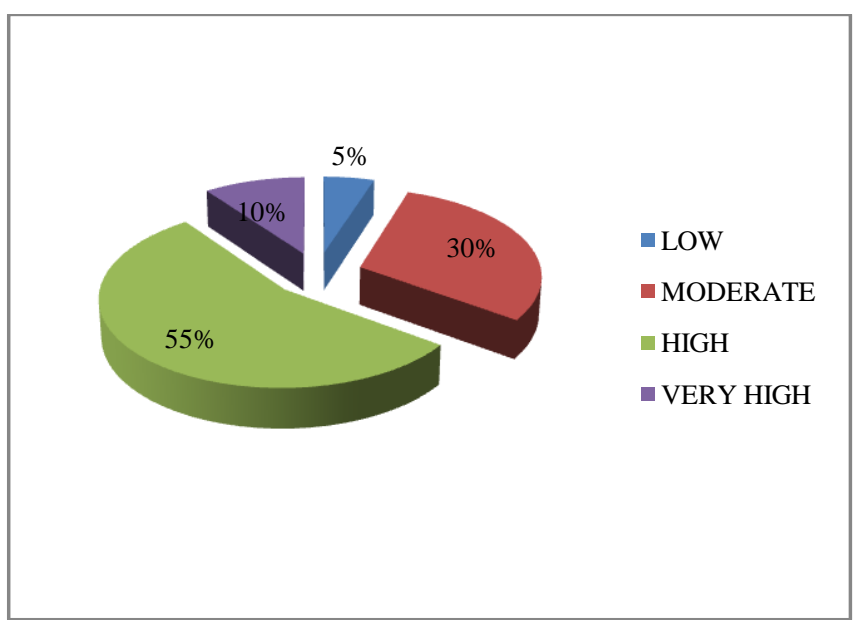

Fig. 5 Company has developed a culture that emphasizes quality

From the above figure 5, we can conclude that majority of the respondents felt that the company had developed a culture that emphasized quality. $65 \%$ of the respondents felt so from high to very high extent. $30 \%$ felt that it was to a moderate extent while $5 \%$ felt that it was to a low extent.

\subsection{The Number of Employees Participating on} Quality Teams has increased

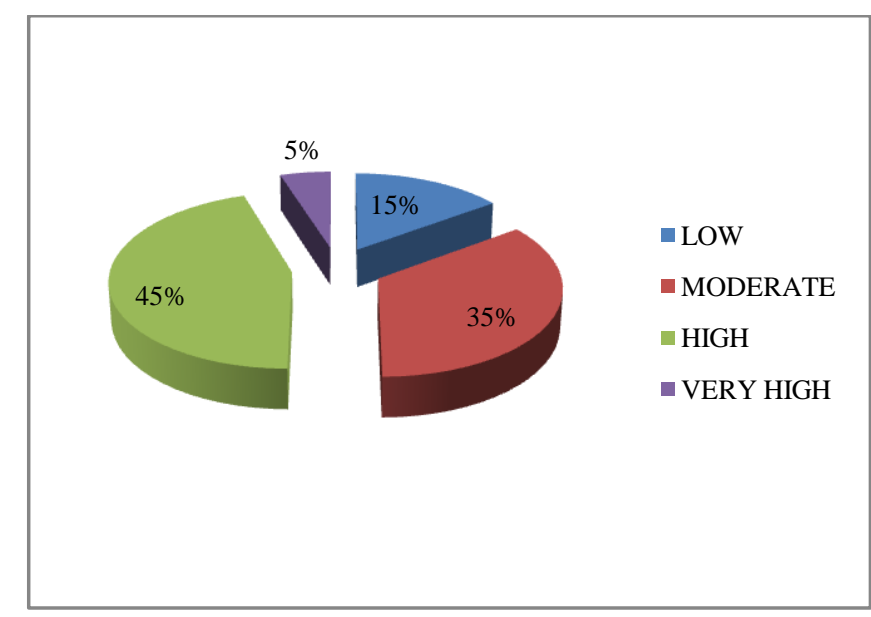

Fig. 6 Increase in number of employees participating on quality teams

$5 \%$ of the respondents felt that the number of employees participating on quality teams had increased to very high extent, while $45 \%$ of them felt it was to a high extent. As can be observed from the figure $6,35 \%$ respondents felt that increase in number was to a moderate extent. 


\subsection{Employee Satisfaction has increased}

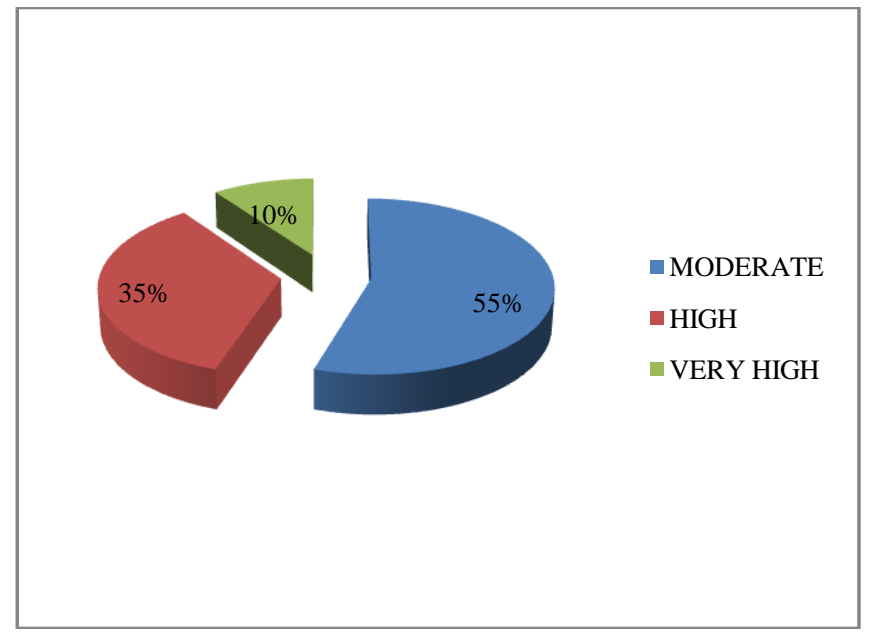

Fig. 7 Increase in Employee Satisfaction

Majority of the respondents agreed that after implementing TQM employee satisfaction had increased to a great extent. $45 \%$ of them felt that employee satisfaction had increased to a high or very high extent while $55 \%$ felt that it has increased to a moderate extent. In general it was observed that $100 \%$ respondents claimed increase in the employee satisfaction as a result of implementation of TQM. (Fig.7)

\subsection{Employee Turnover has decreased}

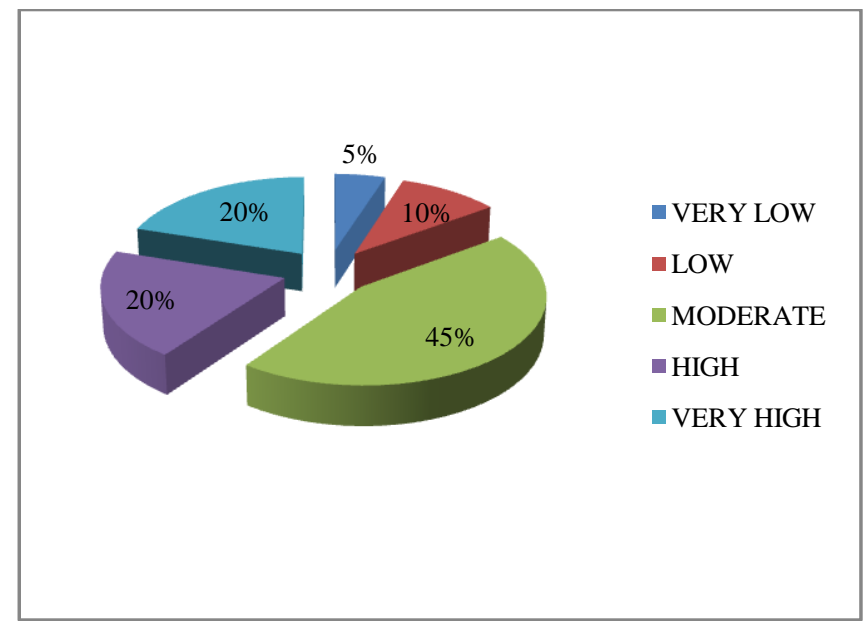

Fig. 8 Decrease in Employee Turnover

As can be seen from the above figure $8,20 \%$ of the respondents felt that after implementing TQM, employee turnover has decreased to a very high extent while $45 \%$ felt that it has decreased to a moderate extent. Another $20 \%$ felt that it has decreased to a high extent whereas only $10 \%$ felt that it has decreased to a low extent. As there is a very close connection between employee satisfaction and employee turnover, reduction in the employee turnover is clearly justified.

\subsection{Partnership with Suppliers has Improved Quality of Incoming Materials}

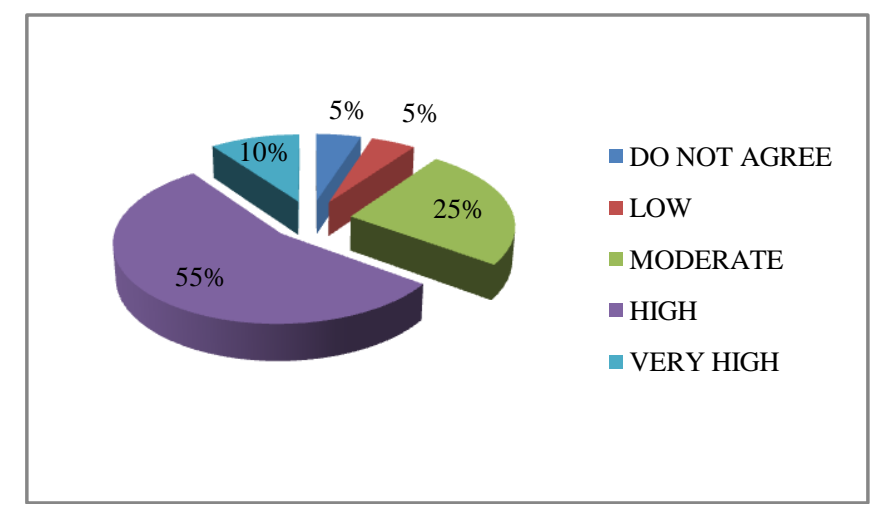

Fig. 9 Improvement in quality of incoming materials by partnership with suppliers

As a result of TQM implementation it is observed that $55 \%$ of the respondents could observe improvement in quality of incoming material to a high extent due to partnerships with suppliers, while $10 \%$ felt that it has improved to a very high extent as can be seen from the above figure 9 . Only $25 \%$ of the respondents felt that it has improved moderately.

\section{CONCLUSIONS}

It may be concluded that SMEs can gain a lot if they follow TQM principles. Table 1 shows the ranking of benefits derived by the firms.

Table -1: Ranking of TQM benefits [15]

\begin{tabular}{|l|l|l|l|l|l|}
\hline $\begin{array}{l}\text { Benefits } \\
\text { Derived }\end{array}$ & $\mathbf{N}$ & Minimum & Maximum & Mean & $\begin{array}{l}\text { Std. } \\
\text { Deviation }\end{array}$ \\
\hline $\begin{array}{l}\text { The number of } \\
\text { products/service } \\
\text { defects, errors } \\
\text { or failures have } \\
\text { decreased }\end{array}$ & 20 & 3 & 5 & 4.10 & .553 \\
\hline $\begin{array}{l}\text { Customer } \\
\text { satisfaction has } \\
\text { shown } \\
\text { improvement }\end{array}$ & 20 & 3 & 5 & 4.10 & .553 \\
\hline $\begin{array}{l}\text { The number of } \\
\text { customer } \\
\text { complaints has } \\
\text { decreased }\end{array}$ & 20 & 3 & 5 & 3.85 & .587 \\
\hline $\begin{array}{l}\text { Company has } \\
\text { developed a } \\
\text { culture that } \\
\text { emphasizes } \\
\text { quality }\end{array}$ & 20 & 2 & 5 & 3.70 & .733 \\
\hline $\begin{array}{l}\text { Employee } \\
\text { satisfaction has } \\
\text { increased }\end{array}$ & 20 & 3 & 586 \\
\hline
\end{tabular}




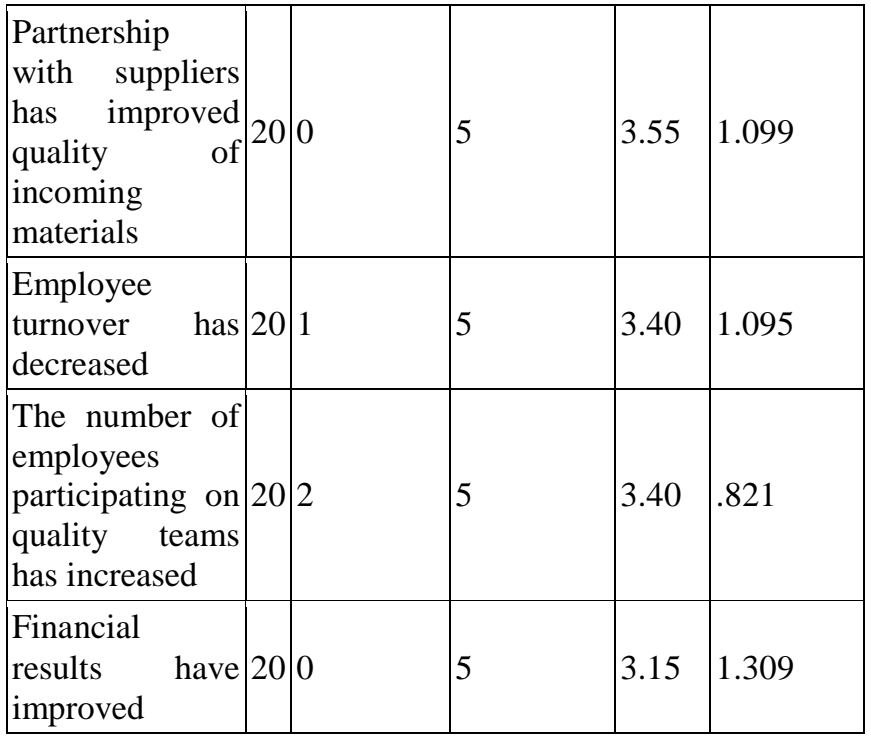

The greatest benefit of them is reduction in the number of products/ service defects, errors or failures; and with this obviously customer satisfaction shown improvement. This is quite seen from the next benefit in the order that the number of customer complaints has reduced. Well, this is only possible if the company has developed a culture that emphasizes quality. Employee satisfaction has gone up and with that it is very obvious that the employee turnover has gone down. TQM also helped in improving relationship with the suppliers, which helped in getting better quality of incoming materials. It also helped in improvement in the financial results of the firms. [15]

\section{REFERENCES}

[1] Demirbag, M., T. E. T. M. \& Zaim, S., An analysis of the relationship between TQM implementation and organizational performance, Journal of Manufacturing Technology and Management, 2006,Vol. 17(6), pp.829-847

[2] Christofi, P., S. S. \& Bodnar, G., The integration of TQM into sustainability, Internal Auditing, 2008, Vol.23(1), pp.33-39

[3] Total Quality Management, Dale H. Besterfield, Glen H. Besterfield, Hemand Urdhwareshe et al, Third Edition, 2011, Pearson Education in South Asia

[4] Chong, Y. Lee., G. A. K., "TQM in small manufacturers: An exploratory study in China" International Journal of Quality and Reliability Management, 2003, pp. 715-197

[5] Sohail, S. A. H., "TQM practices and organizational performances of SMEs in Malaysia's Benchmarking” An International Journal, 2003, pp. 37-53

[6] Mahadevappa, B. A. K., "Quality Management practices in Indian ISO 9000 certified companies: an empirical evaluation", Total Quality Management \& Business Excellence, Nov -2011, Vol.1/Issue4/Article No-8/63-77, pp. 295- 305

[7] Sousa, S. D., A. E. S. P. A. R. A. G., "Performance measures and quality tools in Portugese Small And Medium Enterprises: survey results”, Total Quality
Management and Business Excellence, 2005, pp. 277- 307

[8] Bou, J. C., B., “Total Quality Management, highcommitment human resource strategy and firm performance: an empirical study", Total Quality Management And Business Excellence, 2005, pp. 7186

[9] Shivakumar B. Burli, B. B. Kotturshettar, Priyanka Kalghatgi, Impact of Quality Management Practices on the Organizational Performance of Small and Medium Scale Manufacturing Industries, International Journal Of Management Research and Review, Nov -2011, Volume-1/Issue-4/Article No-8, Article No-8/ pp 63-77

[10] S.D.Kalpande, Dr.R.C.Gupta \& Dr. M.D. Dandekar, Identification of Strengths and Weaknesses of Indian manufacturing SMEs, International Journal for Quality research, 2010, Vol.4,No.4, pp. 263-269

[11] Rao, V.M., T. C., Strategic Quality Management, Malcolm Baldrige and European quality awards and ISO 9000 certification, International Journal of Quality \& Reliability Management, 1996, Vol.13, pp.8-38

[12] D.J. Prajogo, A.S. Sohal, The relationship between organization strategy, Total Quality Management (TQM), and organization performance- the mediating role of TQM, European Journal of Operational Research, 2006, Vol.168, pp.35-50

[13] L.W. Philips, D.R. Chang, R. B., Product quality, cost position, and business performance: A test of some key hypotheses, Journal of Marketing, 1983, Vol.37 (2), pp.26-43

[14] Deming, W., Quality, Productivity, and Competitive Position, Massachusetts Institute, Center for Advanced Engineering Study, Cambridge, MA, 1982

[15] Yogesh A. Chauhan, Ph.D. Thesis titled "Quality Engineering approach through ISO9001 and TQM: A comparative study of Small and Medium scale manufacturing Industries.” 